\title{
ON THE STABILITY OF TWO-DIMENSIONAL FLOWS CLOSE TO THE SHEAR
}

\author{
O.V. Kirichenko ${ }^{1}, S . V$. Revina $^{1,2}$
}

${ }^{1}$ Southern Federal University, Rostov-on-Don, Russian Federation

${ }^{2}$ Southern Mathematical Institute of the Vladikavkaz Scientific Centre of the Russian

Academy of Sciences, Russian Federation

E-mails: okirichenko@sfedu.ru,svrevina@sfedu.ru

\begin{abstract}
We consider the stability problem for two-dimensional spatially periodic flows of general form, close to the shear, assuming that the ratio of the periods tends to zero, and the average of the velocity component corresponding to the "long" period is non-zero. The first terms of the long-wavelength asymptotics are found. The coefficients of the asymptotic expansions are explicitly expressed in terms of some Wronskians and integral operators of Volterra type, as in the case of shear basic flow. The structure of eigenvalues and eigenfunctions for the first terms of asymptotics is identified, a comparison with the case of shear flow is made. We study subclasses of the considered class of flows in which the general properties of the qualitative behavior of eigenvalues and eigenfunctions are found. Plots of neutral curves are constructed. The most dangerous disturbances are numerically found. Fluid particle trajectories in the self-oscillatory regime in the linear approximation are given.

Keywords: long-wave asymptotics; stability of two-dimensional viscous flows; neutral stability curves.
\end{abstract}

\section{Introduction}

Mathematical models that describe two-dimensional or spatially periodic fluid flows are widely used to study various natural phenomena in the atmosphere and the ocean [1]. In [2], a model of two-dimensional creeping motion of viscous liquid in a flat channel is considered. Based on a priori estimates, the solution of the problem is constructed and its properties are investigated. The Kolmogorov problem for a two-dimensional viscous fluid under the influence of spatially periodic external forces is considered in [3]. Using the Galerkin method, stationary and spatially periodic solutions are found numerically. In [4] nonstationary time-periodic structures are obtained using long-wave perturbations of the Kolmogorov flow.

In this paper we consider the two-dimensional $\left(\boldsymbol{x}=\left(x_{1}, x_{2}\right) \in \mathbb{R}^{2}\right)$ viscous incompressible flow driven by an external forces field $\boldsymbol{F}(\boldsymbol{x}, t)$ that is periodic in $x_{1}$ and $x_{2}$ with periods $\ell_{1}$ and $\ell_{2}$, respectively. The flow is described by the Navier-Stokes equations

$$
\frac{\partial \boldsymbol{v}}{\partial t}+(\boldsymbol{v}, \nabla) \boldsymbol{v}-\nu \Delta \boldsymbol{v}=-\nabla p+\boldsymbol{F}(\boldsymbol{x}, t), \quad \operatorname{div} \boldsymbol{v}=0
$$

where $\nu=1 / R e$ is the kinematic viscosity and $R e$ is the Reynolds number. The period $\ell_{1}=2 \pi$, and the ratio of the periods is characterized by the wave number $\alpha: \ell_{2}=2 \pi / \alpha$, $\alpha \rightarrow 0$. Let $\langle f\rangle$ denote the average with respect to $x_{1},\langle\langle f\rangle\rangle$ denote the average over the period rectangle $\Omega=\left[0, \ell_{1}\right] \times\left[0, \ell_{2}\right]$ : 


$$
\langle f\rangle=\frac{1}{\ell_{1}} \int_{0}^{\ell_{1}} f(\boldsymbol{x}, t) d x_{1}, \quad\langle\langle f\rangle\rangle(t)=\frac{1}{|\Omega|} \int_{\Omega} f(\boldsymbol{x}, t) d x_{1} d x_{2} .
$$

The spatial average velocity is assumed to be given: $\langle\langle\boldsymbol{v}\rangle\rangle=\boldsymbol{q}$. The velocity field is assumed to be periodic in $x_{1}, x_{2}$ with the same periods $\ell_{1}, \ell_{2}$ as the field of external forces.

A longwave asymptotics $(\alpha \rightarrow 0)$ is constructed for the stability problem of the steady flow close to the shear, which will be called the basic flow:

$$
\boldsymbol{V}=\left(\alpha V_{1}\left(x_{2}\right), V_{2}\left(x_{1}\right)\right), \quad\left\langle V_{2}\right\rangle \neq 0
$$

The class of flows under consideration generalizes the Kolmogorov flow with a sinusoidal velocity profile

$$
\boldsymbol{V}=\left(0, \gamma \sin \left(x_{1}\right)\right)
$$

The problem of investigating the stability of a two-dimensional flow under the action of spatially periodic force was proposed by A.N. Kolmogorov in his seminar. The instability of the Kolmogorov flow with respect to long-wave perturbations in the linear approximation was proved in [5]. The long-wave asymptotic behavior of the stability problem for twodimensional parallel flows of general form

$$
\boldsymbol{V}=\left(0, V_{2}\left(x_{1}\right)\right), \quad\left\langle V_{2}\right\rangle \neq 0
$$

was considered in [6]. Research [7] is devoted to the study of self-oscillations arising in the loss of stability of parallel flows of a viscous fluid affected by long wavelength perturbations. In [8], the main terms of the asymptotics of the secondary self-oscillatory regimes in the case of the basic flow close to parallel were found, but general rules in coefficient expressions were not obtained.

In [9] recurrence formulas for finding the $k$-th term of the long wavelength asymptotic for the stability of steady shear flows were derived in the case of nonzero average. The coefficients of the expansions are explicitly expressed in terms of some Wronskians, as well as integral operators of Volterra type. It is shown that the eigenvalues of the linear spectral problem are odd functions of the parameter $\alpha$, and the critical viscosity is an even function. In the particular case, when the deviation of the velocity from its mean value $V_{2}(x)-\left\langle V_{2}\right\rangle$ is an odd function of $x$, the coefficients of expansion of the eigenvalues in series in powers of $\alpha$, starting from the third, are zero and the eigenvalues can be found exactly: $\sigma_{1,2}= \pm i m\langle V\rangle \alpha, m \neq 0$. In [10], recurrence formulas for finding the $k$ th term of the long-wave asymptotics for the stability of two-dimensional basic shear flows of a viscous incompressible fluid with zero average are derived.

The aim of this paper is to generalize the results [9] related to shear flows in the case of basic flows close to shear.

\section{Equations up to $\alpha^{k}$}

Let $H$ denote the subspace of functions $f \in L_{2}\left(0, \ell_{1}\right)$ that are orthogonal to unity: $\langle f\rangle=0$. The operator $I: H \rightarrow H$ is the inverse of the differentiation operator and is completely continuous:

$$
I f=\int_{0}^{x} f(s) d s-\left\langle\int_{0}^{x} f(s) d s\right\rangle
$$

Вестник ЮУрГУ. Серия «Математическое моделирование

и программирование» (Вестник ЮУрГУ ММП). 2019. Т. 12, № 3. С. 28-41 
Let $W(f, g)$ denote the Wronskian of functions $f$ and $g$, the auxiliary function $\theta$ characterizes the deviation of the second component of velocity from its average value:

$$
W(f, g)=f \frac{d g}{d x}-g \frac{d f}{d x}, \quad \frac{d^{2} \theta}{d x^{2}}=V_{2}-\left\langle V_{2}\right\rangle, \quad\langle\theta\rangle=0
$$

Looking for a solution $(\widetilde{\mathbf{v}}, \widetilde{p})$ of linearized on the basic flow (1) perturbation equation in the form of normal oscillations, we obtain the linear eigenvalue problem (here and below, $\left.x=x_{1}, z=\alpha x_{2}\right)$ :

$$
\begin{aligned}
& \sigma \varphi_{1}+\alpha^{2} \varphi_{2} \frac{d V_{1}}{d z}+\alpha V_{1}(z) \frac{\partial \varphi_{1}}{\partial x}+\alpha V_{2}(x) \frac{\partial \varphi_{1}}{\partial z}-\nu\left(\frac{\partial^{2} \varphi_{1}}{\partial x^{2}}+\alpha^{2} \frac{\partial^{2} \varphi_{1}}{\partial z^{2}}\right)=-\frac{\partial P}{\partial x} \\
& \sigma \varphi_{2}+\varphi_{1} \frac{d V_{2}}{d x}+\alpha V_{1}(z) \frac{\partial \varphi_{2}}{\partial x}+\alpha V_{2}(x) \frac{\partial \varphi_{2}}{\partial z}-\nu\left(\frac{\partial^{2} \varphi_{2}}{\partial x^{2}}+\alpha^{2} \frac{\partial^{2} \varphi_{2}}{\partial z^{2}}\right)=-\alpha \frac{\partial P}{\partial z} \\
& \frac{\partial \varphi_{1}}{\partial x}+\alpha \frac{\partial \varphi_{2}}{\partial z}=0, \quad \int_{0}^{2 \pi} \varphi_{1}(x, z) d z=0, \quad\left\langle\varphi_{2}\right\rangle=0 .
\end{aligned}
$$

The value of the parameter $\nu$ at which one or several eigenvalues $\sigma$ lie on the imaginary axis is called critical.

The unknown perturbations of velocity $\varphi(x, z)$, the function $P(x, z)$, the eigenvalues $\sigma$ and the critical viscosity $\nu$ are sought in the form of series in powers of $\alpha$ :

$$
\begin{array}{cc}
\sigma(\alpha)=\sum_{k=0}^{\infty} \sigma_{k} \alpha^{k}, \quad \nu=\nu_{*}+\sum_{k=1}^{\infty} \nu_{k} \alpha^{k}, \\
\boldsymbol{\varphi}=\sum_{k=0}^{\infty} \boldsymbol{\varphi}^{k} \alpha^{k}, \quad P=\sum_{k=0}^{\infty} P^{k} \alpha^{k} .
\end{array}
$$

We substitute $(7)-(8)$ in $(4)-(6)$ and equate the coefficients with the same powers of $\alpha$. Up to $\alpha^{0}$ from the continuity equation (6) we deduce that $\varphi_{1}^{0}=\varphi_{1}^{0}(z)$. Then it follows from (4) that $\sigma_{0} \varphi_{1}^{0}(z)=-\frac{\partial P^{0}}{\partial x}$. Whence $\sigma_{0}=0$ and $P^{0}=P^{0}(z)$. From (5) we find the function $\varphi_{2}^{0}$, that has the same form as in the case of shear basic flow:

$$
\varphi_{2}^{0}=\frac{1}{\nu_{*}} \varphi_{1}^{0}(z) a_{0}(x), \quad a_{0}(x)=\frac{d \theta}{d x} .
$$

Averaging equation (4) and equating the coefficients up to $\alpha^{1}$, we obtain:

$$
\sigma_{1} \varphi_{1}^{0}(z)+\left\langle V_{2}\right\rangle \frac{d \varphi_{1}^{0}}{d z}=0
$$

From (10) we find $\sigma_{1}=i m\left\langle V_{2}\right\rangle, \quad \varphi_{1}^{0}(z)=e^{-i m z}$, where $m \neq 0$ is the wave number.

Up to $\alpha^{k}, k \geqslant 1$, from $(4)-(6)$ we derive the following system of equations:

$$
\begin{aligned}
\nu_{*} \frac{\partial^{2} \varphi_{1}^{k}}{\partial x^{2}}= & \frac{\partial P^{k}}{\partial x}+\sum_{j=1}^{k} \sigma_{j} \varphi_{1}^{k-j}-\sum_{j=1}^{k-1} \nu_{j} \frac{\partial^{2} \varphi_{1}^{k-j}}{\partial x^{2}}-\sum_{j=0}^{k-2} \nu_{j} \frac{\partial^{2} \varphi_{1}^{k-2-j}}{\partial z^{2}}+ \\
& +V_{2}(x) \frac{\partial \varphi_{1}^{k-1}}{\partial z}+\frac{d V_{1}}{d z} \varphi_{2}^{k-2}+V_{1}(z) \frac{\partial \varphi_{1}^{k-1}}{\partial x}
\end{aligned}
$$




$$
\begin{gathered}
\nu_{*} \frac{\partial^{2} \varphi_{2}^{k}}{\partial x^{2}}=\sum_{j=1}^{k} \sigma_{j} \varphi_{2}^{k-j}-\sum_{j=1}^{k} \nu_{j} \frac{\partial^{2} \varphi_{2}^{k-j}}{\partial x^{2}}-\sum_{j=0}^{k-2} \nu_{j} \frac{\partial^{2} \varphi_{2}^{k-2-j}}{\partial z^{2}}+ \\
+\left\{W\left(\varphi_{1}^{k}, \theta^{\prime \prime}\right)\right\}+\left\langle V_{2}\right\rangle \frac{\partial \varphi_{2}^{k-1}}{\partial z}+V_{1}(z) \frac{\partial \varphi_{2}^{k-1}}{\partial x}+\frac{\partial\left\{P^{k-1}\right\}}{\partial z} \\
\frac{\partial \varphi_{1}^{k}}{\partial x}+\frac{\partial \varphi_{2}^{k-1}}{\partial z}=0, \quad \int_{0}^{2 \pi} \varphi_{1}^{k} d z=0, \quad\left\langle\varphi_{2}^{k}\right\rangle=0 .
\end{gathered}
$$

Here, the sum is assumed to extend over those values of $j$ for which the upper boundary is not less than the lower one. The solvability condition for equations (11) - (12) is that the average of the right-hand side over period $\ell_{1}$ is zero. Averaging (11) for $k \geq 2$, we get the equation for finding $\left\langle\varphi_{1}^{k-1}\right\rangle$ :

$$
\begin{aligned}
& \left\langle V_{2}\right\rangle\left(i m\left\langle\varphi_{1}^{k-1}\right\rangle+\frac{d\left\langle\varphi_{1}^{k-1}\right\rangle}{d z}\right)=\nu_{k-2} \frac{d^{2} \varphi_{1}^{0}}{d z^{2}}-\frac{d^{2}}{d z^{2}}\left\langle\theta^{\prime} \varphi_{2}^{k-2}\right\rangle-\sigma_{k} \varphi_{1}^{0}(z)- \\
& -\sum_{j=3}^{k-1} \sigma_{j}\left\langle\varphi_{1}^{k-j}\right\rangle+\sum_{j=0}^{k-3} \nu_{j} \frac{d^{2}}{d z^{2}}\left\langle\varphi_{1}^{k-2-j}\right\rangle \equiv F_{k-1}(z) .
\end{aligned}
$$

We will call (14) the averaged equation up to $\alpha^{k}$. On the other hand, the solvability condition of equation (14) serves to find $\nu_{k-2}$ and $\sigma_{k}$ :

$$
\left\langle\left\langle F_{k-1}(z) e^{i m z}\right\rangle\right\rangle=0
$$

For $k=2$, from the solvability condition (15) for equation (14) we find: $\nu_{*}^{2}=$ $\left\langle\theta^{\prime 2}\right\rangle, \quad \sigma_{2}=0$. For the values $\nu_{*}^{2}$ and $\sigma_{2}$ found, the right-hand side of (14) is zero. To exclude trivial nonuniqueness, we put $\left\langle\varphi_{1}^{1}\right\rangle=0$, as in the case of shear flow [9].

The scheme for finding the $k$-th term of the asymptotics for $k \geq 1$ is as follows. Suppose $\varphi_{2}^{k-1}, \varphi_{1}^{k-1}, P^{k-1}, \sigma_{k+1}, \nu_{k-1},\left\langle\varphi_{1}^{k}\right\rangle$ are known. Applying the integral operator $I$ defined by (3), from the continuity equation (13) we find

$$
\varphi_{1}^{k}=-I\left(\frac{\partial \varphi_{2}^{k-1}}{\partial z}\right)+\left\langle\varphi_{1}^{k}\right\rangle .
$$

Substituting the $\varphi_{1}^{k}$ found in (11), we define $P^{k}$ up to an average values. After this, from (12) we find $\varphi_{2}^{k}$. The values found in the $k$-th step allow writing the solvability condition for the $(k+2)$-th term of the asymptotics. From the averaged equations up to $\alpha^{k+2}$ we find $\sigma_{k+2}, \nu_{k},\left\langle\varphi_{1}^{k+1}\right\rangle$. Then the process is repeated.

For a non-parallel basic flow (1), the coefficients of expansion of the critical viscosity $\nu$ and the eigenvalues $\sigma$ have the following structure:

$$
\nu_{k}=\left[\nu_{k}\right]+\widetilde{\nu_{k}}, \quad \sigma_{k+2}=\left[\sigma_{k+2}\right]+\widetilde{\sigma_{k+2}}
$$

where the square brackets are used to denote the coefficients of viscosity and eigenvalues in the case of basic shear flow, and the wave is used to denote additional term. If $V_{1}(z)=0$ then that additional term is equal to zero. It will be shown later that components of 
eigenfunctions and pressure $\varphi_{1}^{k}, P^{k}$ for $k=1,2,3$ and $\varphi_{2}^{k}$ for $k=1,2$ have the same structure:

$$
\begin{aligned}
\varphi_{1}^{k} & =\left[\varphi_{1}^{k}\right]+\widetilde{\varphi_{1}^{k}}+\left\langle\varphi_{1}^{k}\right\rangle, \\
\varphi_{2}^{k} & =\left[\varphi_{2}^{k}\right]+\widetilde{\varphi_{2}^{k}}, \\
P^{k} & =\left[P^{k}\right]+\widetilde{P^{k}}+\left\langle P^{k}\right\rangle,
\end{aligned}
$$

while for large values of $k$, additional terms appear in the expressions of the eigenfunctions $\varphi$ and the pressure $P$. These terms depend on the mean values of previous coefficients.

\section{Asymptotic Terms up to $\alpha^{1}$}

Putting $k=1$ in (16), taking into account the expressions of $\varphi_{2}^{0}$ in $(9)$ and $\left\langle\varphi_{1}^{1}\right\rangle=0$, we find $\varphi_{1}^{1}$

$$
\varphi_{1}^{1}=-I\left(\frac{\partial \varphi_{2}^{0}}{\partial z}\right)=-\frac{1}{\nu_{*}} \frac{d \varphi_{1}^{0}}{d z} I\left(a_{0}\right)
$$

and $P^{1}$, which coincides with the one found in the case of shear basic flow:

$$
P^{1}=q_{1}(x) \frac{d \varphi_{1}^{0}}{d z}+\left\langle P^{1}\right\rangle, \quad q_{1}(x)=-2 \frac{d \theta}{d x} .
$$

Represent $\varphi_{2}^{1}$ as a sum (19), where $\left[\varphi_{2}^{1}\right]$ and $\widetilde{\varphi_{2}^{1}}$ satisfy the equations:

$$
\nu_{*} \frac{\partial^{2}\left[\varphi_{2}^{1}\right]}{\partial x^{2}}=\left\{W\left(\varphi_{1}^{1}, \theta^{\prime \prime}\right)\right\}-\nu_{1} \frac{\partial^{2} \varphi_{2}^{0}}{\partial x^{2}}, \quad \nu_{*} \frac{\partial^{2} \widetilde{\varphi_{2}^{1}}}{\partial x^{2}}=V_{1}(z) \frac{\partial \varphi_{2}^{0}}{\partial x} .
$$

(Here and below the deviation of a periodic function from its period-average value is denoted by curly brackets: $\{F\}=F(x)-\langle F\rangle)$. Coefficient $\left[\varphi_{2}^{1}\right]$ coincides with the coefficient $\varphi_{2}^{1}$ for the shear basic flow except for the term containing $\nu_{1}$, which has not been determined yet. Suppose $a_{1}(\theta)=I\left\{W\left(\theta^{\prime}, \theta\right)\right\}[9]$, then

$$
\left[\varphi_{2}^{1}\right]=\frac{1}{\nu_{*}^{2}} \frac{d \varphi_{1}^{0}}{d z} a_{1}(\theta)-\frac{\nu_{1}}{\nu_{*}} \varphi_{2}^{0}, \quad \widetilde{\varphi_{2}^{1}}=\frac{1}{\nu_{*}} V_{1}(z) I\left(\varphi_{2}^{0}\right)=\frac{1}{\nu_{*}^{2}} \varphi_{1}^{0}(z) V_{1}(z) I\left(a_{0}\right) .
$$

For $k=3$, we transform the right-hand side of (14), taking the known values $\left[\nu_{1}\right]=0$ and $\left[\sigma_{3}\right]=-\frac{i m^{3}}{\nu_{*}^{2}}\left\langle\theta^{\prime} a_{1}\right\rangle$ into account:

$$
F_{2}(z)=2 \widetilde{\nu_{1}} \frac{d^{2} \varphi_{1}^{0}}{d z^{2}}-\frac{d^{2}}{d z^{2}}\left\langle\theta^{\prime} \widetilde{\varphi_{2}^{1}}\right\rangle-\widetilde{\sigma_{3}} \varphi_{1}^{0}(z)
$$

From the solvability condition (15), taking into account the orthogonality of $\theta^{\prime}$ and $\widetilde{\varphi_{2}^{1}}$, we obtain $\widetilde{\nu_{1}}=0, \quad \widetilde{\sigma_{3}}=0$. As in the case of shear basic flow, $\nu_{1}=0, \sigma_{3}=\left[\sigma_{3}\right]$. Hence the right-hand side of (14) is zero. To exclude trivial non-uniqueness, we put $\left\langle\varphi_{1}^{2}\right\rangle=0$. In the particular case when $\theta(x)$ is an odd function, $\sigma_{3}=0$, as in the case of shear basic flow. 


\section{Asymptotic Terms up to $\alpha^{2}$}

We derive $\varphi_{1}^{2}$ from the continuity equation (16), representing $\varphi_{1}^{2}$ as a sum (18), where

$$
\left[\varphi_{1}^{2}\right]=-\frac{1}{\nu_{*}^{2}} \frac{d^{2} \varphi_{1}^{0}}{d z^{2}} I\left(a_{1}\right), \quad \widetilde{\varphi_{1}^{2}}=-\frac{1}{\nu_{*}} \frac{\partial}{\partial z}\left(V_{1}(z) I^{2}\left(\varphi_{2}^{0}\right)\right) .
$$

From (11) for $k=2$, we conclude that $\left[P^{2}\right]$ coincides with the one found in the case of shear flow:

$$
\left[P^{2}\right]=\frac{1}{\nu_{*}} \frac{d^{2} \varphi_{1}^{0}}{d z^{2}} q_{2}, \quad q_{2}=-a_{1}+I\left\{\theta^{\prime \prime} I\left(a_{0}\right)\right\}
$$

and $\widetilde{P^{2}}$ satisfies the equation

$$
\frac{\partial \widetilde{P^{2}}}{\partial x}=\nu_{*} \frac{\partial^{2} \widetilde{\varphi_{1}^{2}}}{\partial x^{2}}-\varphi_{2}^{0} \frac{d V_{1}}{d z}-V_{1}(z) \frac{\partial \varphi_{1}^{1}}{\partial x},
$$

from which, applying the integral operator $I$, we find

$$
\widetilde{P^{2}}=-2 \frac{d V_{1}}{d z} I\left(\varphi_{2}^{0}\right)=-\frac{2}{\nu_{*}} \varphi_{1}^{0}(z) \frac{d V_{1}}{d z} I\left(a_{0}\right) .
$$

Let consider the equation (12) for $k=2$. We represent $\varphi_{2}^{2}$ as a sum (19), where $\left[\varphi_{2}^{2}\right]$ and $\widetilde{\varphi_{2}^{2}}$ satisfy the equations

$$
\begin{gathered}
\nu_{*} \frac{\partial^{2}\left[\varphi_{2}^{2}\right]}{\partial x^{2}}=\frac{d^{2} \varphi_{1}^{0}}{d z^{2}} q_{1}(\theta)+\left\{W\left(\left[\varphi_{1}^{2}\right], \theta^{\prime \prime}\right)\right\}-\nu_{*} \frac{\partial^{2} \varphi_{2}^{0}}{\partial z^{2}}-\nu_{2} \frac{\partial^{2} \varphi_{2}^{0}}{\partial x^{2}} \\
\nu_{*} \frac{\partial^{2} \widetilde{\varphi_{2}^{2}}}{\partial x^{2}}=\frac{1}{\nu_{*}}\left\{W\left(\widetilde{\varphi_{1}^{2}}, \theta^{\prime \prime}\right)\right\}+\frac{\left\langle V_{2}\right\rangle}{\nu_{*}} \frac{d V_{1}}{d z} I\left(\varphi_{2}^{0}\right)+\frac{1}{\nu_{*}} V_{1}(z) \frac{\partial \varphi_{2}^{1}}{\partial z}
\end{gathered}
$$

Taking into account already known expressions of $\varphi_{2}^{0}$ and $\varphi_{1}^{2}$, we find $\varphi_{2}^{2}$ :

$$
\begin{aligned}
& {\left[\varphi_{2}^{2}\right]=\frac{1}{\nu_{*}^{3}} \frac{d^{2} \varphi_{1}^{0}}{d z^{2}} a_{2}(\theta)-\frac{\nu_{2}}{\nu_{*}} \varphi_{2}^{0}(x, z),} \\
& a_{2}(\theta)=I^{2}\left[\left\{W\left(\theta^{\prime \prime}, I a_{1}\right)\right\}+\nu_{*}^{2}\left(q_{1}(\theta)-a_{0}(\theta)\right)\right] .
\end{aligned}
$$

The coefficient $a_{2}(\theta)(22)$ is the same as in the case of shear basic flow; $\left[\varphi_{2}^{2}\right]$ matches structure with the corresponding expression of the shear basic flow. As it will be shown below, the coefficient $\nu_{2}$ differs from the one found in the case of shear flow.

Applying the integral operator $I$ twice, from (21) we deduce

$$
\widetilde{\varphi_{2}^{2}}=\frac{1}{\nu_{*}} I^{2}\left\{W\left(\widetilde{\varphi_{1}^{2}}, \theta^{\prime \prime}\right)\right\}+\frac{\left\langle V_{2}\right\rangle}{\nu_{*}} \frac{d V_{1}}{d z} I^{3}\left(\varphi_{2}^{0}\right)+\frac{1}{\nu_{*}} V_{1}(z) I\left(\varphi_{2}^{1}\right) .
$$

From (14) for $k=4$ considering $\left[\sigma_{4}\right]=0, \quad\left[\nu_{2}\right]=-\frac{m^{2}}{2 \nu_{*}^{3}}\left\langle\theta^{\prime} a_{2}\right\rangle$ we get

$$
F_{3}(z)=2 \widetilde{\nu_{2}} \frac{d^{2} \varphi_{1}^{0}}{d z^{2}}-\frac{d^{2}}{d z^{2}}\left\langle\theta^{\prime} \widetilde{\varphi_{2}^{2}}\right\rangle-\widetilde{\sigma_{4}} \varphi_{1}^{0}(z) .
$$


To verify the solvability condition (15), we need the expression for $\left\langle\left\langle\widetilde{\varphi_{2}^{2}} e^{i m z}\right\rangle\right\rangle$ :

$$
\begin{aligned}
& \left\langle\left\langle\widetilde{\varphi_{2}^{2}} e^{i m z}\right\rangle\right\rangle=\frac{i m}{\nu_{*}^{3}}\left\langle\left\langle V_{1}\right\rangle\right\rangle g_{2}(x)+\frac{1}{\nu_{*}^{3}}\left\langle\left\langle V_{1}^{2}\right\rangle\right\rangle f_{2}(x), \\
& g_{1}=I a_{0}, \quad g_{2}(x)=I^{2}\left\{W\left(I g_{1}, \theta^{\prime \prime}\right)\right\}-I a_{1}, \quad f_{2}(x)=I g_{1}(x)=I^{2} a_{0} .
\end{aligned}
$$

Separating the real and imaginary parts in the solvability condition (15) for $k=4$, we obtain

$$
\widetilde{\nu_{2}}=\frac{1}{2 \nu_{*}^{3}}\left\langle\left\langle V_{1}^{2}\right\rangle\right\rangle\left\langle\theta^{\prime} f_{2}\right\rangle=-\frac{1}{2 \nu_{*}^{3}}\left\langle\left\langle V_{1}^{2}\right\rangle\right\rangle\left\langle\theta^{2}\right\rangle, \quad \widetilde{\sigma_{4}}=\frac{i m^{3}}{\nu_{*}^{3}}\left\langle\left\langle V_{1}\right\rangle\right\rangle\left\langle\theta^{\prime} g_{2}\right\rangle .
$$

Note that the imaginary part of (23) contains the mean values of the odd degrees of $V_{1}$, and the the real part contains the mean values of the even degrees of $V_{1}$.

The solution of (14) for $k=4$ will be sought in the form $\left\langle\varphi_{1}^{3}\right\rangle=c(z) e^{-i m z}$, where $c(z)$ is a $2 \pi$-periodic function. Let $I_{z}$ denote the operator $I$ defined by (3) with variable upper limit $z$. Condition (15) uniquely determines the function $c(z)$. Then $c(z)=e^{-i m z} I_{z}\left(F_{3}(z) e^{i m z}\right) /\left\langle V_{2}\right\rangle$.

Further, in each of the orders, two special cases will be considered.

Case 1. $\theta(x)$ is an odd function (it means that the deviation $V_{2}-\left\langle V_{2}\right\rangle$ is an odd function). Hence $g_{1}(x)$ is odd and from (23) it follows that $g_{2}(x)$ and $f_{2}(x)$ are even functions.

Case 2. $V_{1}(z)$ is an odd function of variable $z$. Then $\left\langle\left\langle V_{1}(z)\right\rangle\right\rangle=0$ and $\widetilde{\sigma}_{4}=0$.

\section{Asymptotic Terms up to $\alpha^{3}$} where

From the continuity equation (13) for $k=3$ we find $\varphi_{1}^{3}$, in the form of a sum (18),

$$
\begin{aligned}
& {\left[\varphi_{1}^{3}\right]=-\frac{1}{\nu_{*}^{3}} \frac{d^{3} \varphi_{1}^{0}}{d z^{3}} I a_{2}-\frac{\nu_{2}}{\nu_{*}} \varphi_{1}^{1},} \\
& \widetilde{\varphi_{1}^{3}}=-\frac{1}{\nu_{*}} I^{3}\left\{W\left(\frac{\partial \widetilde{\varphi_{1}^{2}}}{\partial z}, \theta^{\prime \prime}\right)\right\}-\frac{\left\langle V_{2}\right\rangle}{\nu_{*}^{2}} \frac{\partial}{\partial z}\left(\frac{d V_{1}}{d z} I^{4} \varphi_{2}^{0}\right)-\frac{1}{\nu_{*}} \frac{\partial}{\partial z}\left(V_{1}(z) I^{2} \varphi_{2}^{1}\right) .
\end{aligned}
$$

$P^{3}$ can be represented as a sum (20) where

$$
\left[P^{3}\right]=\frac{1}{\nu_{*}^{2}} \frac{d^{3} \varphi_{1}^{0}}{d z^{3}} q_{3}(\theta), \quad q_{3}(\theta)=-a_{2}+I\left\{\theta^{\prime \prime} I\left(a_{1}\right)\right\}-\nu_{*}^{2} I^{2} a_{0},
$$

and $\widetilde{P^{3}}$ is determined by expression

$$
\widetilde{P^{3}}=-I\left\{\theta^{\prime \prime} \frac{\partial \widetilde{\varphi_{1}^{2}}}{\partial z}\right\}-I^{2}\left\{W\left(\frac{\partial \widetilde{\varphi_{1}^{2}}}{\partial z}, \theta^{\prime \prime}\right)\right\}-2 \frac{d V_{1}}{d z} I\left(\varphi_{2}^{1}\right) .
$$

As in [10] we use the following notation. If the function $f$ is expressed in terms of a linear combination of the functions $\varphi_{1}^{0}(z)$ and its derivatives with coefficients depending on $x$, then by $f\left(\left\langle\varphi_{1}^{k}\right\rangle\right)$ we denote the expression that coincides with the expression $f$ if $\varphi_{1}^{0}(z)$ is replaced by $\left\langle\varphi_{1}^{k}\right\rangle(z)$. Since $\left\langle\varphi_{1}^{3}\right\rangle \neq 0$, it is convenient to represent $\varphi_{2}^{3}$ as a sum

$$
\varphi_{2}^{3}=\left[\varphi_{2}^{3}\right]+\widetilde{\varphi_{2}^{3}}+\varphi_{2}^{0}\left(\left(\left\langle\varphi_{1}^{3}\right\rangle\right)\right)
$$


where $\left[\varphi_{2}^{3}\right]$ has a form

$$
\begin{aligned}
& {\left[\varphi_{2}^{3}\right]=\frac{1}{\nu_{*}^{4}} \frac{d^{3} \varphi_{1}^{0}}{d z^{3}} a_{3}(\theta)-2 \frac{\widetilde{\nu_{2}}}{\nu_{*}}\left[\varphi_{2}^{1}\right]-\frac{\nu_{3}}{\nu_{*}} \varphi_{2}^{0},} \\
& a_{3}(\theta)=I^{2}\left[\left\{W\left(\theta^{\prime \prime}, I a_{2}\right)\right\}+\nu_{*}^{2}\left(q_{2}-a_{1}\right)\right]-\frac{\left\langle\theta^{\prime} a_{2}\right\rangle}{\nu_{*}^{2}} a_{1}(\theta)-\left\langle\theta^{\prime} a_{1}\right\rangle I^{2}\left(a_{0}\right) .
\end{aligned}
$$

Then $\widetilde{\varphi_{2}^{3}}$ is determined from the following equality:

$$
\begin{aligned}
& \widetilde{\varphi_{2}^{3}}=\frac{1}{\nu_{*}} I^{2}\left(\frac{\partial\left\{\widetilde{P^{2}}\right\}}{\partial z}\right)+\frac{1}{\nu_{*}} I^{2}\left\{W\left(\widetilde{\varphi_{1}^{3}}, \theta^{\prime \prime}\right)\right\}+\left\langle V_{2}\right\rangle I^{2}\left(i m \widetilde{\varphi_{2}^{2}}+\widetilde{\frac{\partial \varphi_{2}^{2}}{\partial z}}\right)- \\
& -\frac{\nu_{2}}{\nu_{*}} \widetilde{\varphi_{2}^{1}}-I^{2} \frac{\partial^{2} \widetilde{\varphi_{2}^{1}}}{\partial z^{2}}+\frac{1}{\nu_{*}} V_{1}(z) I\left(\varphi_{2}^{2}\right) .
\end{aligned}
$$

To find $\left\langle\varphi_{1}^{4}\right\rangle, \nu_{3}$ and $\sigma_{5}$, we write $F_{4}$ taking into account $\left[\nu_{3}\right]=0, \quad\left[\sigma_{5}\right]=\frac{i m}{\nu_{*}^{4}}\left\langle\theta^{\prime} a_{3}(\theta)\right\rangle$ :

$$
F_{4}(z)=2 \widetilde{\nu_{3}} \frac{d^{2} \varphi_{1}^{0}}{d z^{2}}-\frac{d^{2}}{d z^{2}}\left\langle\theta^{\prime} \widetilde{\varphi_{2}^{3}}\right\rangle-\left(\widetilde{\sigma_{5}}+\frac{2 \widetilde{\nu_{2}}}{\nu_{*}} \sigma_{3}\right) \varphi_{1}^{0}(z) .
$$

Separating the real and imaginary parts (15) for $k=6$, we obtain

$$
\begin{aligned}
& \widetilde{\nu_{3}}=-\frac{m^{2}}{2 \nu_{*}^{4}}\left\langle\left\langle V_{1}\right\rangle\right\rangle\left\langle\theta^{\prime} g_{3}\right\rangle, \quad \widetilde{\sigma_{5}}=\frac{i m^{3}}{\nu_{*}^{4}}\left\langle\left\langle V_{1}^{2}\right\rangle\right\rangle\left\langle\theta^{\prime} f_{3}\right\rangle-\frac{2 \widetilde{\nu_{2}}}{\nu_{*}} \sigma_{3}, \\
& g_{3}=I^{2}\left\{W\left(I g_{2}, \theta^{\prime \prime}\right)\right\}+I a_{2}, \quad f_{3}=I^{2}\left\{W\left(I f_{2}, \theta^{\prime \prime}\right)\right\}+I g_{2} .
\end{aligned}
$$

Now, unlike the previous step (24), the expression for the viscosity expansion coefficients includes the averages of the odd powers of $V_{1}$, and the eigenvalue coefficient contains the averages of even powers of $V_{1}$. The solution of (14) for $k=5$ has the form $\left\langle\varphi_{1}^{4}\right\rangle=e^{-i m z} I_{z}\left(F_{4}(z) e^{i m z}\right) /\left\langle V_{2}\right\rangle$, similar to the order $\alpha^{3}$.

Case 1. $\theta(x)$ is an odd function. Then it follows from (26) that $f_{3}(x)$ and $g_{3}(x)$ are odd functions, hence $\nu_{3}=0$ and, taking into account $\sigma_{3}=0$, we find $\sigma_{5}=\left[\sigma_{5}\right]=0$.

Case 2. $V_{1}(z)$ is an odd function of $z$. Then $\left\langle\left\langle V_{1}(z)\right\rangle\right\rangle=0$ and $\nu_{3}=0$, as in the case of shear basic flow.

\section{Asymptotic Terms up to $\alpha^{4}$}

From the continuity equation (13) for $k=4$ and $\varphi_{2}^{3}$ defined in (25), we find $\varphi_{1}^{4}$ :

$$
\varphi_{1}^{4}=\left[\varphi_{1}^{4}\right]+\widetilde{\varphi_{1}^{4}}+\varphi_{1}^{1}\left(\left\langle\varphi_{1}^{3}\right\rangle\right)+\left\langle\varphi_{1}^{4}\right\rangle
$$

where $\left[\varphi_{1}^{4}\right], \widetilde{\varphi_{1}^{4}}$ are defined by formulas:

$$
\begin{aligned}
& {\left[\varphi_{1}^{4}\right]=-\frac{1}{\nu_{*}^{4}} \frac{d^{4} \varphi_{1}^{0}}{d z^{4}} I a_{3}(\theta)-2 \frac{\widetilde{\nu_{2}}}{\nu_{*}}\left[\varphi_{1}^{2}\right]-\frac{\nu_{3}}{\nu_{*}} \varphi_{1}^{1},} \\
& \widetilde{\varphi_{1}^{4}}=\frac{2}{\nu_{*}} \frac{\partial^{2}}{\partial z^{2}}\left(\frac{d V_{1}}{d z} I^{4} \varphi_{2}^{0}\right)-\frac{1}{\nu_{*}} I^{3}\left\{W\left(\frac{\partial \widetilde{\varphi_{1}^{3}}}{\partial z}, \theta^{\prime \prime}\right)\right\}+ \\
& +\frac{\left\langle V_{2}\right\rangle}{\nu_{*}} I^{2}\left(i m \widetilde{\varphi_{1}^{3}}+\frac{\partial \widetilde{\varphi_{1}^{3}}}{\partial z}\right)-\frac{\nu_{2}}{\nu_{*}} \widetilde{\varphi_{1}^{2}}-I^{2}\left(\frac{\partial^{2} \widetilde{\varphi_{1}^{2}}}{\partial z^{2}}\right)-\frac{1}{\nu_{*}} \frac{\partial}{\partial z}\left(V_{1}(z) I^{2} \varphi_{2}^{2}\right) .
\end{aligned}
$$


The pressure $P^{4}$ is representable as the sum $P^{4}=\left[P^{4}\right]+\widetilde{P^{4}}+P^{1}\left(\left(\left\langle\varphi_{1}^{3}\right\rangle\right)\right)+\left\langle P^{4}\right\rangle$, where

$$
\begin{aligned}
& {\left[P^{4}\right]=\frac{1}{\nu_{*}^{3}} \frac{d^{4} \varphi_{1}^{0}}{d z^{4}} q_{4}(x)-\frac{\nu_{2}}{\nu_{*}}\left[P^{2}\right]} \\
& \widetilde{P^{4}}=-I^{2}\left(\frac{\partial^{2}\left\{\widetilde{P^{2}}\right\}}{\partial z^{2}}\right)-I^{2}\left\{W\left(\frac{\partial \widetilde{\varphi_{1}^{3}}}{\partial z}, \theta^{\prime \prime}\right)\right\}-I\left\{\theta^{\prime \prime} \frac{\partial \widetilde{\varphi_{1}^{3}}}{\partial z}\right\}-2 \frac{d V_{1}}{d z} I \varphi_{2}^{2},
\end{aligned}
$$

and $q_{4}$ is found in [9].

Representing $\varphi_{2}^{4}$ as the sum $\varphi_{2}^{4}=\left[\varphi_{2}^{4}\right]+\widetilde{\varphi_{2}^{4}}+\varphi_{2}^{1}\left(\left\langle\varphi_{1}^{3}\right\rangle\right)+\varphi_{2}^{0}\left(\left\langle\varphi_{1}^{4}\right\rangle\right)$ and taking into account

$$
\left[\varphi_{2}^{4}\right]=\frac{1}{\nu_{*}^{5}} \frac{d^{4} \varphi_{1}^{0}}{d z^{4}} a_{4}+\frac{\sigma_{4}}{\nu_{*}} I^{2} \varphi_{2}^{0}-\frac{\widetilde{\nu_{2}}}{\nu_{*}}\left[\varphi_{2}^{2}\right]-\frac{2 \nu_{3}}{\nu_{*}}\left[\varphi_{2}^{1}\right]-\frac{2 \widetilde{\nu_{2}}}{\nu_{*}^{2}} I^{2}\left\{W\left(\left[\varphi_{1}^{2}\right], \theta^{\prime \prime}\right)\right\}-\frac{\nu_{4}}{\nu_{*}} \varphi_{2}^{0},
$$

we find $\widetilde{\varphi_{2}^{4}}$ :

$$
\begin{aligned}
& \widetilde{\varphi_{2}^{4}}=\frac{1}{\nu_{*}} I^{2}\left(\frac{\partial \widetilde{P^{3}}}{\partial z}\right)+\frac{\left\langle V_{2}\right\rangle}{\nu_{*}} I^{2}\left(i m \widetilde{\varphi_{2}^{3}}+\widetilde{\frac{\partial \varphi_{2}^{3}}{\partial z}}\right)+\frac{1}{\nu_{*}} I^{2}\left\{W\left(\widetilde{\varphi_{1}^{4}}, \theta^{\prime \prime}\right)\right\}+ \\
& +\frac{\sigma_{3}}{\nu_{*}} \widetilde{\varphi^{1}}-\frac{\nu_{2}}{\nu_{*}} \widetilde{\varphi_{2}^{2}}-\frac{\nu_{3}}{\nu_{*}} \widetilde{\varphi_{2}^{1}}-I^{2}\left(\frac{\partial^{2} \widetilde{\varphi_{2}^{2}}}{\partial z^{2}}\right)+\frac{1}{\nu_{*}} V_{1}(z) I \varphi_{2}^{3}+\frac{1}{\nu_{*}} I^{2} a_{0}(x) F_{3}(z) .
\end{aligned}
$$

To find $\left\langle\varphi_{1}^{5}\right\rangle, \sigma_{6}$ and $\nu_{4}$, we write out the right-hand side of the averaged equation up to $\alpha^{6}$ :

$$
F_{5}(z)=\nu_{4} \frac{d^{2} \varphi_{1}^{0}}{d z^{2}}-\frac{d^{2}}{d z^{2}}\left\langle\theta^{\prime} \varphi_{2}^{4}\right\rangle-\sigma_{6} \varphi_{1}^{0}(z)-\sigma_{3}\left\langle\varphi_{1}^{3}\right\rangle+\nu_{*} \frac{d^{2}\left\langle\varphi_{1}^{4}\right\rangle}{d z^{2}}
$$

Taking into account $\left[\nu_{4}\right]=\frac{m^{4}}{2 \nu_{*}^{5}}\left\langle\theta^{\prime} a_{4}(\theta)\right\rangle, \quad\left[\sigma_{6}\right]=0,(27)$ yields

$$
\begin{aligned}
& F_{5}(z)=2 \widetilde{\nu_{4}} \frac{d^{2} \varphi_{1}^{0}}{d z^{2}}-\frac{\sigma_{4}}{\nu_{*}} \frac{d^{2}}{d z^{2}}\left\langle\theta^{\prime} I^{2} \varphi_{2}^{0}\right\rangle+\widetilde{\nu_{2}} \frac{d^{2}}{d z^{2}}\left\langle\theta^{\prime}\left[\varphi_{2}^{2}\right]\right\rangle+ \\
& +2 \frac{\nu_{3}}{\nu_{*}} \frac{d^{2}}{d z^{2}}\left\langle\theta^{\prime}\left[\varphi_{2}^{1}\right]\right\rangle+2 \frac{\widetilde{\nu_{2}}}{\nu_{*}^{2}} \frac{d^{2}}{d z^{2}}\left\langle\theta^{\prime} I^{2}\left\{W\left(\left[\varphi_{1}^{2}\right], \theta^{\prime \prime}\right)\right\}\right\rangle-\frac{d^{2}}{d z^{2}}\left\langle\theta^{\prime} \widetilde{\varphi_{2}^{4}}\right\rangle-\widetilde{\sigma_{6}} \varphi_{1}^{0}(z) .
\end{aligned}
$$

Separating the real and imaginary parts of (15) and considering the previous coefficients, we obtain

$$
\begin{aligned}
& \widetilde{\nu_{4}}=\frac{1}{2} \operatorname{Re}\left\langle\left\langle\left\langle\theta^{\prime} \widetilde{\varphi_{2}^{4}}\right\rangle e^{i m z}\right\rangle\right\rangle-\frac{\widetilde{\nu_{2}}}{2 \nu_{*}}\left(\left[\nu_{2}\right]-\widetilde{\nu_{2}}\right)-\frac{\widetilde{\nu_{2}} m^{2}}{\nu_{*}^{4}}\left\langle\theta^{\prime} I^{2}\left\{W\left(I a_{1}, \theta^{\prime \prime}\right)\right\}\right\rangle, \\
& \widetilde{\sigma_{6}}=m^{2} \operatorname{Im}\left\langle\left\langle\left\langle\theta^{\prime} \widetilde{\varphi_{2}^{4}}\right\rangle e^{i m z}\right\rangle\right\rangle-\frac{\sigma_{4} m^{2}}{\nu_{*}}\left\langle\theta^{2}\right\rangle-2 \frac{\nu_{3} \sigma_{3}}{\nu_{*}} .
\end{aligned}
$$

Introduce the notation:

$$
\begin{aligned}
& h_{1}=-I^{2}\left\{W\left(f_{2}, \theta^{\prime \prime}\right)\right\}+\left\langle V_{2}\right\rangle I f_{2}, \quad h_{2}=-I^{2}\left\{W\left(I h_{1}, \theta^{\prime \prime}\right)\right\}+\left\langle V_{2}\right\rangle I^{2} h_{1}, \\
& f_{4}=I^{2}\left\{W\left(I f_{3}, \theta^{\prime \prime}\right)\right\}+I g_{3}, \quad g_{4}=I^{2}\left\{W\left(I g_{3}, \theta^{\prime \prime}\right)\right\}-I a_{3} .
\end{aligned}
$$


Then the expression $\operatorname{Re}\left\langle\left\langle\left\langle\theta^{\prime} \widetilde{\varphi_{2}^{4}}\right\rangle e^{i m z}\right\rangle\right\rangle$ has the following structure

$$
R e\left\langle\left\langle\left\langle\theta^{\prime} \widetilde{\varphi_{2}^{4}}\right\rangle e^{i m z}\right\rangle\right\rangle=\frac{1}{\nu_{*}^{5}}\left\langle\left\langle V_{1}^{2}\right\rangle\right\rangle\left\langle\theta^{\prime} A_{1}\right\rangle+\frac{1}{\nu_{*}^{5}}\left\langle\left\langle\left(\frac{d V_{1}}{d z}\right)^{2}\right\rangle\right\rangle\left\langle\theta^{\prime} A_{2}\right\rangle+\frac{1}{\nu_{*}^{5}}\left\langle\left\langle V_{1}^{4}\right\rangle\right\rangle\left\langle\theta^{\prime} I^{2} f_{2}\right\rangle,
$$

where $A_{1}, A_{2}$ are determined by the formulas

$$
A_{1}=-m^{2} f_{4}-3 \nu_{2} \nu_{*} f_{2}+2 m^{2} I^{2} f_{2}, \quad A_{2}=3 \nu_{*}^{2} I^{2} f_{2}-I h_{2} .
$$

Similarly, $\operatorname{Im}\left\langle\left\langle\left\langle\theta^{\prime} \widetilde{\varphi_{2}^{4}}\right\rangle e^{i m z}\right\rangle\right\rangle$ has a form:

$$
\operatorname{Im}\left\langle\left\langle\left\langle\theta^{\prime} \widetilde{\varphi_{2}^{4}}\right\rangle e^{i m z}\right\rangle\right\rangle=\frac{m}{\nu_{*}^{3}}\left\langle\left\langle V_{1}\right\rangle\right\rangle\left\langle\theta^{\prime} B_{1}\right\rangle+\frac{m}{\nu_{*}^{5}}\left\langle\left\langle V_{1}^{3}\right\rangle\right\rangle\left\langle\theta^{\prime} B_{2}\right\rangle,
$$

where $B_{1}, B_{2}$ are determined by the formulas:

$$
\begin{aligned}
& B_{1}=I^{3}\left\{\theta^{\prime \prime} f_{2}\right\}+I^{2}\left\{W\left(f_{2}, \theta^{\prime \prime}\right)\right\}+I^{2}\left\{W\left(I^{2} f_{2}, \theta^{\prime \prime}\right)\right\}+I^{2} g_{2}- \\
& -\frac{\nu_{2}}{\nu_{*}}\left(2 I^{2}\left\{W\left(I g_{1}, \theta^{\prime \prime}\right)\right\}+g_{2}\right)-\frac{1}{\nu_{*}^{2}} g_{4}, \\
& B_{2}=I^{2}\left\{W\left(I^{2} f_{2}, \theta^{\prime \prime}\right)\right\}+I f_{3} .
\end{aligned}
$$

Note that in the order $\alpha^{4}$, as in the order $\alpha^{2}$, the expression for the viscosity expansion coefficients includes the averages of the even powers of $V_{1}$, and the eigenvalue coefficient contain the averages of odd powers of $V_{1}$. As in the previous order, for $k=6$ the solution of the equation (14) has the form: $\left\langle\varphi_{1}^{5}\right\rangle=e^{-i m z} I_{z}\left(F_{5}(z) e^{i m z}\right) /\left\langle V_{2}\right\rangle$.

Case 1. $\theta(x)$ is an odd function. Then $f_{4}(x)$ and $g_{4}(x)$ are even functions.

Case 2. $V_{1}(z)$ is an odd function of $z$. Then $\left\langle\left\langle V_{1}(z)\right\rangle\right\rangle=0,\left\langle\left\langle V_{1}^{3}(z)\right\rangle\right\rangle=0$ and $\sigma_{6}=0$. Using the obtained formulas, we construct graphs of curves of neutral stability $y=$ $\frac{1}{\nu(\alpha)}$. For general flows, as well as for special cases considered above, there is a similar qualitative picture. The most dangerous are perturbations at $m=1$ (Fig. 1).

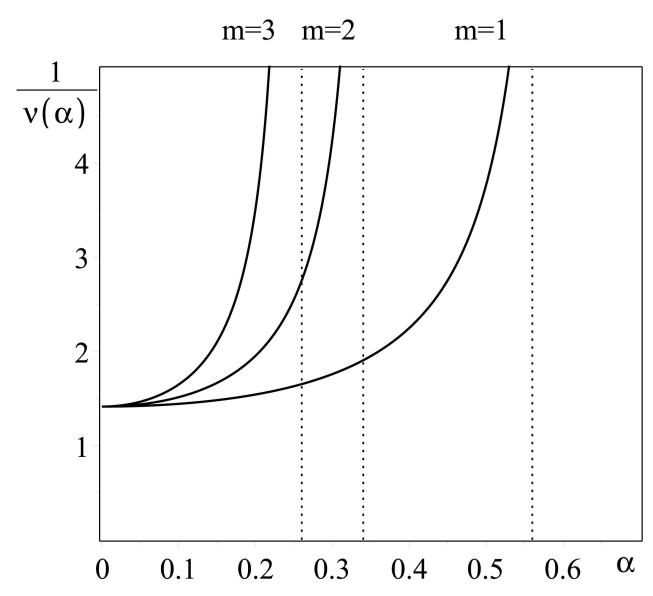

Fig. 1. Neutral stability curves

The found asymptotics allows us to investigate the trajectories of the motion of passive impurity particles in the secondary self-oscillatory flow [8]. The trajectories of particles in the linear approximation satisfy the equation

$$
\dot{\mathbf{x}}=\mathbf{V}(\mathbf{x})+\mathbf{u}(\mathbf{x}, t), \quad \mathbf{u}(\mathbf{x}, t)=\varphi e^{i \omega t}+\varphi^{*} e^{-i \omega t} .
$$

The qualitative behavior of the trajectories is presented in Fig. 2. 


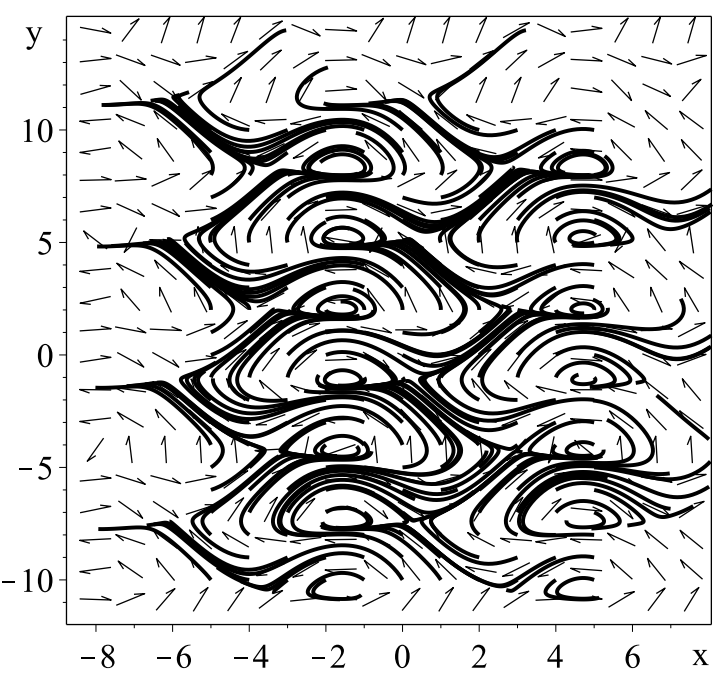

Fig. 2. Trajectories of the motion of particles of a passive admixture

\section{Conclusion}

The first terms of the long-wavelength asymptotics with respect to the parameter $\alpha$ of linear spectral problem for a class of non-parallel flows close to the shear are found. A comparison with the case of the shear basic flow is made. It is shown that the expansion coefficients in terms of $\alpha$ eigenvalues and the critical value of viscosity have the form (17), where the square brackets are used to denote the coefficients of viscosity and eigenvalues in the case of basic shear flow, and the wave is used to denote additional term. If $V_{1}(z)=0$ then that additional term is equal to zero.

The first terms of the expansion in series in the parameter $\alpha$ of velocity $\varphi_{1}^{0}(z), \varphi_{2}^{0}(x, z)$, $\varphi_{1}^{1}(x, z)$ and pressure $P^{0}, P^{1}$ coincide with the coefficients for the case of shear basic flow. Average values $\left\langle\varphi_{1}^{1}\right\rangle=\left\langle\varphi_{1}^{2}\right\rangle=0$, as in the case of shear basic flow, but $\left\langle\varphi_{1}^{k}\right\rangle \neq 0$ for $k \geqslant 3$.

The coefficients of the decomposition in a series of eigenfunctions have the following structure:

$$
\begin{aligned}
& \varphi_{1}^{k}=\left[\varphi_{1}^{k}\right]+\widetilde{\varphi_{1}^{k}}+\varphi_{1}^{1}\left(\left\langle\varphi_{1}^{k-1}\right\rangle\right)+\left\langle\varphi_{1}^{k}\right\rangle, \\
& \varphi_{2}^{k}=\left[\varphi_{2}^{k}\right]+\widetilde{\varphi_{2}^{k}}+\varphi_{2}^{1}\left(\left\langle\varphi_{1}^{k-1}\right\rangle\right)+\varphi_{2}^{0}\left(\left\langle\varphi_{1}^{k}\right\rangle\right),
\end{aligned}
$$

and the coefficients of decomposition in a series of pressure have the following structure

$$
P^{k}=\left[P^{k}\right]+\widetilde{P^{k}}+P^{1}\left(\left\langle\varphi_{1}^{k-1}\right\rangle\right)+\left\langle P^{k}\right\rangle .
$$

Here $k=1,2,3,4$. The expressions in square brackets $\left[\varphi_{i}^{k}\right],\left[P^{k}\right]$ are the solutions of the same equations, as in the case of shear basic flow and coincide with corresponding coefficients if $\widetilde{\nu_{j}}=0, \widetilde{\sigma_{j}}=0$.

If at least one of the conditions is met: $\theta(x)$ is odd or $V_{1}(z)$ is odd, then critical value of viscosity $V_{1}(z)$ is an even function of $\alpha$ as in the case of shear basic flow (up to order $k=4$ inclusively):

$$
\nu(\alpha)=\nu_{*}+\nu_{2} \alpha^{2}+\nu_{4} \alpha^{4}+O\left(\alpha^{5}\right), \quad \alpha \rightarrow 0 .
$$


If $\theta(x)$ is odd, then odd components of the eigenvalue decomposition, starting with the third, are zero:

$$
\sigma(\alpha)=\sigma_{1} \alpha+\sigma_{4} \alpha^{4}+\sigma_{6} \alpha^{6}+O\left(\alpha^{7}\right), \quad \alpha \rightarrow 0 .
$$

If $V_{1}(z)$ is odd, then even components of the eigenvalue decomposition are zero:

$$
\sigma(\alpha)=\sigma_{1} \alpha+\sigma_{3} \alpha^{3}+\sigma_{5} \alpha^{5}+O\left(\alpha^{6}\right), \quad \alpha \rightarrow 0 .
$$

Thus, under both conditions eigenvalues up to terms of order $\alpha^{5}$ have the form

$$
\sigma(\alpha)= \pm i m \alpha\left\langle V_{2}\right\rangle+O\left(\alpha^{5}\right), \quad \alpha \rightarrow 0,
$$

as in a shear basic flow case.

For a basic flow close to a shear of general form the inequality $\nu_{2}<\left[\nu_{2}\right]$ is fulfilled, therefore, the loss of stability of such flows occurs at higher Reynolds numbers, than for shear flow.

Neutral stability curves qualitatively coincide with the corresponding curves for the Kolmogorov-flow (2). The trajectories of the passive admixture, found numerically, consistent with Obukhov's hydrodynamics experiments [11].

\section{References}

1. Dolzhanskii F.V. Lektsii po geofizicheskoj gidrodinamike [Lectures on Geophysical Hydrodynamics]. Moscow, IVM RAN, 2006. (in Russian)

2. Andreev V.K. On the Solution of an Inverse Problem Simulating Two-Dimensional Motion of a Viscous Fluid. Bulletin of the South Ural State University. Series: Mathematical Modelling, Programming and Computer Software, 2016, vol. 9, no. 4, pp. 5-16. DOI: $10.14529 / \mathrm{mmp} 160401$

3. Sun-Chul Kim, Tomoyuki Miyaji, Hisashi Okamoto. Unimodal Patterns Appearing in the Two-Dimensional Navier-Stokes Flows Under General Forcing at Large Reynolds Numbers. Nonlinearity, 2017, vol. 28, no. 9, pp. 234-246.

4. Kalashnik M., Kurgansky M. Nonlinear Dynamics of Long-Wave Perturbations of the Kolmogorov Flow for Large Reynolds Numbers. Ocean Dynamics, 2018, vol. 68, pp. 1001-1012.

5. Meshalkin L.D., Sinai Ia.G. Investigation of the Stability of a Stationary Solution of a System of Equations for the Plane Movement of an Incompressible Viscous Liquid. Journal of Applied Mathematics and Mechanics, 1961, vol. 25, no. 6, pp. 1700-1705.

6. Yudovich V.I. Instability of Viscous Incompressible Parallel Flows with Respect to Spatially Periodic Perturbations. Numerical Methods for Problems in Mathematical Physics, 1966, Moscow, pp. 242-249. (in Russian)

7. Yudovich V.I. Natural Oscillations Arising from Loss of Stability in Parallel Flows of a Viscous Liquid under Longwavelength Periodic Disturbances. Fluid Dynamics, 1973, vol. 8, pp. 26-29.

8. Melekhov A.P., Revina S.V. Onset of Self-Oscillations upon the Loss of Stability of Spatially Periodic Two Dimensional Viscous Fluid Flows Relative to Long-Wave Perturbations. Fluid Dynamics, 2008, vol. 43, no. 2, pp. 203-216.

9. Revina S.V. Recurrence Formulas for Long Wavelength Asymptotics in the Problem of Shear Flow Stability. Computational Mathematics and Mathematical Physics, 2013, vol. 53, no. 8, pp. 1207-1220. DOI: 10.1134/S096554251306016X 
10. Revina S.V. Stability of the Kolmogorov Flow and Its Modifications. Computational Mathematics and Mathematical Physics, 2017, vol. 57, no. 6, pp. 995-1012. DOI: $10.1134 /$ S0965542517020130

11. Obukhov A.M. Kolmogorov Flow and Laboratory Simulation of It. Russian Mathematical Surveys, 1983, vol. 38, no. 4, pp. 113-126.

\title{
ОБ УСТОЙЧИВОСТИ ДВУМЕРНЫХ ТЕЧЕНИЙ, БЛИЗКИХ К СДВИГОВЫМ
}

\author{
О.В. Кириченко ${ }^{1}$, С.В. Ревина ${ }^{1,2}$ \\ ${ }^{1}$ Южный федеральный университет, г. Ростов-на-Дону, Российская Федерация \\ ${ }^{2}$ Южный математический институт Владикавказского научного центра РАН, \\ г. Владикавказ, Российская Федерация
}

\begin{abstract}
Рассматривается задача устойчивости двумерных пространственнопериодических течений общего вида, близких к сдвиговым, в предположении, что отношение периодов стремится к нулю, а среднее скорости вдоль «длинного» периода отлично от нуля. Найдены первые члены длинноволновой асимптотики. Коэффициенты асимптотических разложений явно выражаются через некоторые вронскианы и интегральные операторы типа Вольтерра, как и в сдвиговом случае. Выявлена структура собственных значений и собственных функций для первых членов асимптотики, произведено сравнение со сдвиговым случаем. Исследованы подклассы рассматриваемого класса течений, в которых обнаруживаются общие свойства качественного поведения собственных значений и собственных функций. Построены графики нейтральных кривых. Численно найдены наиболее опасные возмущения. Приведены траектории движения пассивной примеси во вторичном автоколебательном потоке в линейном приближении.
\end{abstract}

Ключевые слова: длинноволновая асимптотика; устойчивость двумерных течений вязкой жидкости; кривые нейтральной устойчивости.

\section{Литература}

1. Должанский, Ф.В. Лекции по геофизической гидродинамике / Ф.В. Должанский. М.: ИВМ РАН, 2006.

2. Андреев, В.К. О решении одной обратной задачи, моделирующей двумерное движение вязкой жидкости / В.К. Андреев // Вестник ЮУрГУ. Серия: Математическое моделирование и программирование. - 2016. - Т. 9, № 4. - С. 5-16.

3. Sun-Chul Kim. Unimodal Patterns Appearing in the Two-Dimensional Navier-Stokes Flows under General Forcing at Large Reynolds Numbers / Sun-Chul Kim, Tomoyuki Miyaji, Hisashi Okamoto // Nonlinearity. - 2017. - V. 28, № 9. - P. 234-246.

4. Kalashnik, M. Nonlinear Dynamics of Long-Wave Perturbations of the Kolmogorov Flow for Large Reynolds Numbers / M. Kalashnik, M. Kurgansky // Ocean Dynamics. - 2018. V. 68. - P. 1001-1012. 
5. Мешалкин, Л.Д. Исследование устойчивости стационарного решения одной системы уравнений плоского движения вязкой жидкости / Л.Д. Мешалкин, Я.Г. Синай // Прикладная математика и механика. - 1961. - Т. 25, № 6. - С. 1140-1143.

6. Юдович, В.И. О неустойчивости параллельных течений вязкой несжимаемой жидкости относительно пространственно-периодических возмущений / В.И. Юдович // Численные методы решения задач математической физики. - М.: Наука, 1966. - С. 242-249.

7. Юдович, В.И. Об автоколебаниях, возникающих при потере устойчивости параллельных течений вязкой жидкости относительно длинноволновых периодических возмущений / В.И. Юдович // Известия АН СССР. Серия: Механика жидкости и газа. - 1973. № 1. - С. 32-35.

8. Мелехов, А.П. Возникновение автоколебаний при потере устойчивости пространственнопериодических двумерных течений вязкой жидкости относительно длинноволновых возмущений / А.П. Мелехов, С.В. Ревина // Известия РАН. Серия: Механика жидкости и газа. - 2008. - № 2. - С. 41-56.

9. Ревина, С.В. Рекуррентные формулы длинноволновой асимптотики задачи устойчивости сдвиговых течений / С.В. Ревина // Журнал вычислительной математики и математической физики. - 2013. - Т. 5, № 8. - С. 1387-1401.

10. Ревина, С.В. Устойчивость течения Колмогорова и его модификаций / С.В. Ревина // Журнал вычислительной математики и математической физики. - 2017. - Т. 57, № 6. C. $1003-1022$.

11. Обухов, А.М. Течение Колмогорова и его лабораторное моделирование / А.М. Обухов // Успехи математических наук. - 1983. - Т. 38, № 4. - С. 101-111.

Ольга Валерьевна Кириченко, аспирант, кафедра вычислительной математики и математической физики, Южный федеральный университет (г. Ростов-на-Дону, Российская Федерация), okirichenko@sfedu.ru.

Светлана Васильевна Ревина, кандидат физико-математических наук, доцент, кафедра вычислительной математики и математической физики, Южный федеральный университет (г. Ростов-на-Дону, Российская Федерация); научный сотрудник, Южный математический институт Владикавказского научного центра РАН (г. Владикавказ, Российская Федерация), svrevina@sfedu.ru.

Поступила в редакицю 11 декабря 2018 г.

Вестник ЮУрГУ. Серия «Математическое моделирование 